April 1979 to 31 March 1984 indicate that 348 homeless males passed through the programme. Of these, 330 males were responsible for 743 admissions following which they were discharged to the day centre where, currently, on average 78 patients attend each month.

The successes and failures of the programme, its problems, deficiencies and limitations, the factors which may militate against its future effectiveness or against the continuance of the programme as it stands and considerations which might provide a basis for the setting up of other costeffective hospital and community-based alternatives will have to be the subject of other publications.

\title{
The Aftermath of the Mental Health Act 1983: Some Preliminary Impressions
}

\author{
T. W. Fenton, Consultant Psychiatrist and Medical Director, Hollymoor Hospital, Northfield, Birmingham
}

A survey of the views of consultant psychiatrists concerning possible difficulties for the practising clinician in the early aftermath of the Mental Health Act 1983 is presented. The number of consultant psychiatrists written to was 118 and the breakdown of responses was as follows: 37 of 79 general psychiatrists replied; 4 of 8 psychogeriatricians replied; 2 of 9 consultant adolescent psychiatrists replied; 2 of 4 forensic psychiatrists replied; and 5 of 18 consultants in mental handicap replied. The letter asked eight questions concerning specific aspects of the Act and invited any comment.

\section{Question 1}

A person may not be regarded as suffering from mental disorder by reason only of dependence on alcohol and drugs. Has this provision had any important consequence for your clinical practice or is it likely to have such consequence in the future?

Thirty-six respondents replied in the negative. Only five foresaw difficulties in the future. There was comment that the exclusion of drug addicts and alcoholics is not likely to cause particular difficulty as persons who, as a result of their addiction have psychotic episodes, may be admitted under appropriate sections of the Act. Some respondents commented that they were not prepared to detain on the grounds of alcohol and drug dependence alone under the provisions of the 1959 Act.

Fear was expressed that social workers may interpret the new provisions too strictly, rejecting compulsory admission if psychosis is the result of alcohol or drug dependence. Two writers described the admission of patients under Section 2 exhibiting alcohol dependence; in one case it was feared DTs might develop if no action was taken, in the other that there was a serious risk of rapid physical deterioration. Both patients applied to a Tribunal and in both cases the Tribunal felt that the Act had been misused. Another respondent described the concern of relatives of two alcoholics that there

- This article is based on a paper presented at the Spring 1984 meeting of the Midlands Division of the College. were no compulsory powers by which patients could be treated although they were creating havoc within their families.

\section{Question 2}

A patient admitted under Section 2 has the right to apply to a Mental Health Review Tribunal within 14 days of admission. The nearest relative can discharge the patient unless the RMO bars discharge by appropriate certification. Have you found that these provisions limit the usefulness of a Section 2 order as a short-term treatment order or are likely to do so in the future?

The majority of respondents found no particular difficulty here, 32 replying in the negative and only nine anticipating some difficulty in the future. Such dissatisfaction as was expressed mainly concerned the time needed for the preparation of reports for, and attendance at, Mental Health Review Tribunals.

\section{Question 3}

Has it been your experience so far, or do you envisage that it will be your experience in the future, that you use a Section 2 order less frequently than the old Section 25 order, and the Section 3 order more frequently than the old Section 26 order?

Patients detained under Section 3 of the 1983 Act can be treated with medication for three months without their consent or a second opinion. The great majority are likely to be well enough to be discharged or treated informally within three months. Given that this, and the possible deterrent of the right of appeal to a Tribunal under Section 2 is so, I wondered if there was a trend towards admitting patients under Section 3 rather than Section 2 and discharging or regrading them to informal status before three months of the order have run. (A Section 3 patient can, of course, also appeal to a Tribunal, but there will be a lengthier delay before the hearing.)

Twenty-six respondents were definite that they did not expect, and 13 that they did sense or anticipate, this trend. 
Some deprecated the use of a Section 3 order to avoid the inconvenience of an early Tribunal hearing. Four respondents felt that the trend was in the opposite direction, that Section 2 was being used more often because it specifically sanctions treatment. One writer felt that he might have become over-scrupulous about detaining patients, perhaps influenced by the trend towards increased freedom of choice for psychotic patients. This has inclined him not to continue detention under Section 3 when a Section 2 order expired, sometimes to the detriment of the patient. He foresaw that ultimately this may make him more inclined to use Section 3 at time of admission, particularly where there had been previous episodes of illness.

\section{Question 4}

The consent to treatment provisions of the Act do not apply in the case of patients admitted under Section 4 orders. Has this made or is it likely to make significant differences to your own clinical practice?

To my surprise the great majority of respondents did not feel this to be worthy of comment, 36 merely indicating a negative response. One respondent commented that it seems odd that in those situations where patients are most likely to require urgent treatment there is no warrant without consent other than Common Law Rules. Only two respondents concluded that the emergency three-day order will in future be used rarely, and that this trend may not always be in the best interest of the patient.

\section{Question 5}

Have you encountered any significant difficulty concerning the operation of Section 5, particularly in regard to the provision which allows that a nominated deputy may act on behalf of the RMO?

Twenty-eight respondents had found no difficulty as yet. Eight anticipated future problems. It was felt that, since only one deputy is allowed, a situation could arise where neither RMO nor deputy might be available within the six hours of the nurse's holding power. The Act was considered ambiguous as to the status of the nominated deputy and the guidelines issued by Lord Colville impractical.

The Psychiatric Division at one hospital concluded that the Colville Guidelines were a slight to the ability and integrity of registrars, particularly when their counterparts in medicine and surgery regularly take more onerous decisions in the management of sick patients. It was felt that it should be possible for a junior doctor to act as the nominated deputy, the level of experience perhaps being that appropriate to approval under Section 12 of the Act. Attention was drawn to recent correspondence in the Bulletin concerning likely difficulties in small psychiatric departments in general hospitals (Bulletin of the Royal College of Psychiatrists, 8, 9; 74; 159).

Consultants who were chairman of Psychiatric Divisions or Medical Staff Committees were asked to give details of their hospital's policy in regard to the RMO's nominated deputy. Replies indicated that ten of the hospitals followed the Colville Guidelines and four allowed the duty junior doctor to deputize for the RMO.

\section{Question 6}

Have you encountered any problems in relation to the operation of Section 5 (4) which grants a holding power to nurses of the prescribed class?

Thirty-six respondents indicated no problems to date. There was a general expectation that its use would be uncommon. One respondent felt that its use would put pressure on the RMO to follow up with an order so as to 'play safe' and support the nursing staff.

\section{Question 7}

What difficulties, if any, have you encountered with the consent to treatment provisions? In particular, have you experienced any difficulty in relation to Section 58 in ensuring that the independent doctor giving the second opinion is able to consult with two other staff members?

Again, the majority response ( 29 respondents) was that there had been no difficulty as yet. Nine anticipated difficulties in the future. There was comment that, although the Act assumes the implementation of the team approach, it is common on long-stay wards in particular for good psychiatric care to be given without involvement of social workers or psychologists. Thus it might be difficult to find the second therapist concerned who is neither doctor nor nurse. On one occasion a Commissioner had consulted a ward maid in order to fulfil his obligation to consult. Concern was expressed about the practical difficulties of ensuring that the appointed doctor is actually able to meet with the other two therapists, particularly in a rural hospital with a large catchment area. It was pointed out that the appointed doctor had on occasion facilitated this task by using the telephone.

One respondent described a peculiar 'chicken and egg' dilemma with a depressed informal patient who needed ECT but who refused consent. The Commission refused to send an appointed doctor until the patient was detained under Section 3. The consultant felt that the only grounds to detain her on an order were to administer ECT legally without her consent, and was concerned that he might detain the patient only to find that the appointed doctor might refuse to endorse the treatment. Whilst one can sympathize with this dilemma, the appointed doctor cannot sign a treatment certificate under Section 58 in relation to an informal patient.

Two consultants in mental handicap drew attention to problems surrounding the concept of informed consent in the case of mentally handicapped patients informally in institutions. One of them wondered to what extent anticonvulsant drugs would be accepted as treatment for mental 
disorder, the reference here obviously being to the intention of the Act that detained patients may only receive without consent those treatments necessary for their mental disorder.

Anxiety was expressed about the outlook for patients who refused further medication should the appointed doctor uphold the patient's decision. It was foreseen that they might become institutionalized through preserving their freedom of choice even though in a psychotic state. Another concern was that such patients may suffer from neglect from an intolerant consultant to employ the procedures required to ensure that they receive needed treatment despite refusal to give consent.

$A$ view was put that requirement for consent or second opinion in the case of medication should apply, as with ECT, throughout the period of detention.

\section{Question 8}

Have you administered ECT as an urgent treatment under Section 62? Do you consider that, if the clinical circumstances of a case warrant it, the Act will allow you to administer ECT as a Section 62 urgent treatment?

Only eight respondents said that to date (February 1984) they had administered ECT under these circumstances. Thirty-three said they would do so should the need arise. A few added that they would also seek a second opinion from the Commission at the same time, or should consent be refused once the immediate emergency was passed. One writer felt that it was not clear whether ECT might be legally regarded as irreversible or hazardous. He suspected that a jury might take a different line from the psychiatrist since ECT is such an emotive subject.

Another respondent described an issue he had taken up with Commissioners. He had felt that the appointed doctor sees himself as not only having a concern with whether consent is informed but also in assessing the validity and applicability of the suggested treatment. The Commissioners had agreed that this attitude did question the clinical freedom of the RMO and had offered assurance that there would be little difficulty in the great majority of cases and that the Commission would not have idiosyncratic views with regard to treatment.

Only three respondents were not prepared to administer ECT as a Section 62 urgent treatment, one asserting that it was incorrect to think of ECT as an emergency treatment. They would be interested to hear of the experience of another writer who described how the appointed doctor had advised on the telephone that ECT should not be given as an emergency treatment though he would not be able to reach the hospital until the following day.

\section{Question 9}

In addition to the specific questions, I asked about other observations. Disappointment was expressed about the new Guardianship order. The 'essential powers' approach, it was felt, diminished the possibilities of control over the client and rendered guardianship less useful as an instrument of management.

Two writers were concerned about the requirement for abnormally aggressive or seriously irresponsible conduct in relation to the definition of mental impairment and severe mental impairment. Both gave examples of situations where a patient was at serious risk of exploitation and neglect, but the Act seemed to preclude action being taken, in the one case to detain the patient in hospital and in the other to put her on a guardianship order.

A forensic psychiatrist commented that the Home Office had become more cautious in its dealings with restricted patients. He suspected that this was because of the power of the special Mental Health Review Tribunal to discharge restricted patients. He instanced a case in which the decision to allow unescorted parole had been postponed until a Tribunal hearing could take place and how two months had passed without any action being taken. He remarked that many colleagues who had dealings with restricted patients were experiencing similar difficulties.

Another respondent remarked how it seemed that, to an increasing degree, social workers were liable to veto orders and bring patients into hospital informally. He found it irritating that they saw no inconsistency in expecting the consultant to take the responsibility of detaining the patient on an order should he prematurely demand discharge or refuse treatment after having come into hospital informally. An increasing reluctance of social workers to act upon an order if the patient could be persuaded to come into hospital informally was mentioned by several respondents in a variety of different contexts.

There was also comment that the training of social workers for approval seemed scanty considering the crucial role they would have under the new legislation.

Finally, and on a lighter note, there was a plaintive cry of protest at the deluge of new forms loosed upon us by Regulations since 30 September 1983.

\section{Hospital inquiry}

I also wrote to the hospital administrators at 16 psychiatric establishments in the West Midlands (in February 1984), limiting my inquiry to traditional mental hospitals and units which could be expected to have a significant number of compulsory admissions, and received 15 replies. The following information was requested: (1) Number of admissions on various orders of the Mental Health Act 1959, or in-patients regraded to Section 5 status, regraded to Section 26 status and also detained under Section 30 in each month during the period October 1982 to September 1983 inclusive; (2) Numbers of admissions on various orders of the Mental Health Act 1983, of in-patients regraded to Section 2 status, regraded to Section 3 status and detained under Section 5 in each month during the period October 1983 to January 1984 inclusive; and (3) Informal admissions 
and total admissions in each month during the period October 1983 to January 1984 inclusive.

Returns showed that the most obvious change since the advent of the new Act was a 60 per cent reduction in admissions on the three-day order, formerly Section 29 now Section 4, plus a parallel and presumably related 40 per cent reduction in regrading in-patients to 28 -day order status (formerly Section 25 , now Section 2). There was a modest (approximately 15 per cent) increase in admissions on the 28-day order, but the diffierence may not be significant. Overall it seemed that total admissions had remained quite constant over the period under consideration, irrespective of which Mental Health Act was in force.

It seems reasonable to assume for this inquiry that, if respondents (42 per cent of the total) are typical of consultants throughout the West Midlands Region, then the introduction of the new Act has so far occasioned few problems and the future is faced with reasonable equanimity.
Although this paper has highlighted doubts and anxieties, those who share them are in the minority. But a note of caution is appropriate. As many respondents pointed out, though they had encountered no difficulties as yet, it had to be recognized that there had been little experience so far. The hospital returns show no striking change in the pattern of admissions nor in the use of the various orders, apart from acceleration of a trend apparent for some time of a reduction in the use of the three-day order. This is now presumably given emphasis by the exclusion of the Section 4 order from the consent to treatment provisions of the 1983 Act and the more stringent criteria which apply to this section.

\section{Acknowledgements}

I wish to express my sincere gratitude to the respondents for the trouble they took and their detailed and interesting replies. I am also grateful to hospital administrators and their medical records officer colleagues for the hospital returns.

\section{A Need for Pastoral Counselling: Report of a Conference}

RoBin Skynner, Group-Analytic Practice, 88 Montagu Mansions, London W1

In November 1983, a Weekend Residential Conference was held at St George's House, Windsor Castle, on the theme 'The Bishop and his Family', to study the need for pastoral counselling, not only of the laity, but of the clergy also. The conference was chaired by the Right Reverend Michael Mann, Dean of Windsor, and attended by 15 Bishops of the Church of England, and their wives.

Mrs Leslie Rimmer, Deputy Director of the Family Policy Studies Centre, presented an outline of research on the present state of marriage and the family in Britain. Next I focused on some of the basic knowledge that the "helping professions' could offer towards pastoral care, the need for carers at all levels to have support available at times, and the value of peer-groups for this purpose. The Right Reverend Hewlett Thompson, Bishop of Willesden, described the three-tier pastoral support scheme operating in the London Diocese, which he has chaired for the London Bishops. The scheme has comprised a number of experienced group leaders seconded from their posts in the helping professions, who lead groups of selected volunteers, including both clergy and laity. When the numbers in these second-tier groups have received sufficient training they begin to run third-tier groups offering support to those involved in pastoral care. The scheme aims at a 'multiplier' effect whereby a limited availability of professional time can benefit a large number of people receiving pastoral support or counselling. He also spoke of the exploratory group that he and his wife Joy (a Group-Analyst and Adviser in Family Education to the Diocese of London) had attended over two and a half years with two other bishops and their wives, which they had asked my wife, Prue, and myself to conduct in order that they could have direct experience of the process themselves.

To give those attending the Conference an impression of what is involved in this kind of group experience, participants divided into small groups conducted by Hewlett, Joy, Prue and myself. After several such meetings, reactions and views were reported at a final plenary session.

There was the usual sharp division between those participants who concluded that group support of this kind was necessary and desirable, and others who felt that it should not be necessary. However, even those most positive to the idea in principle were concerned about the problem of how to go about finding suitably qualified professionals to help in the task.

The need is for experienced people with knowledge of, and ability to impart, basic principles of counselling and family dynamics, together with skills in leading training/support groups of this kind. I have offered to help the Dean of Windsor to compile a list of professionals with suitable experience who might be interested to participate in similar work in their area. Any Bishop who wished to develop pastoral training and support could find out from the Dean those who might be available locally, and would be able to approach them directly and negotiate, if necessary, with their employing authorities.

I should perhaps add that in the London Diocese scheme the work has been made possible through secondment for a few hours each week of NHS or Social Services staff, or it has been on a voluntary basis. It has not been a requirement that the professionals should be members of the Church of England, but a basic sympathy with the purpose of religious teachings generally is obviously desirable.

Those interested should write to the Right Reverend Michael Mann, Dean of Windsor, St George's House, Windsor Castle, Windsor, Berkshire. 